\title{
A Warm Glow in All Parts? Building Local Cause-Affinity as a Strategy for Promoting Charitable Giving
}

\author{
Nadia Bashir, Chris Dayson, Will Eadson, Peter Wells* \\ CRESR, Sheffield Hallam University
}

\begin{abstract}
This paper explores the under-researched phenomenon of local giving initiatives. It does this against a national context where we find levels of giving slow to change over time, variation in levels of giving between places, and the development of a policy agenda which has given insufficient attention to the role places may play. We develop the concept of local cause affinity to understand local giving practices. Through this we reflect on the need to base our understanding of giving on institutional, social and cultural factors alongside economic factors which are considered more in policy-making. It is in this realm that we debate local giving in light of Adam Smith's two apparently contradictory works (The Theory of Moral Sentiments and The Wealth of Nations). As such we ask whether giving is a rational act or an act of love.
\end{abstract}

Key words: altruism; local giving; warm glow; Adam Smith.

The government said there was evidence of a "latent demand to give" and that individuals and businesses needed to be reminded of the "warm glow" resulting from helping others (29/12/10 BBC Website www.bbc.co.uk/news/mobile/ukpolitics-12085506).

How selfish soever man may be supposed, there are evidently some principles in his nature, which interest him in the fortune of others, and render their happiness necessary to him, though he derives nothing from it except the pleasure of seeing it (Adam Smith, 1759, The Theory of Moral Sentiments, p. 9).

Donors retain an expectation that charities exist to serve the needy, yet in reality their own giving decisions are driven by many non-needs based factors. Despite popular beliefs that charitable giving should be directed primarily to the needy, donors often support organisations that promote their own preferences, that help people they feel some affinity with, and that support causes that relate to their own life experiences (Breeze, 2010 p. 53). 
p. 140. A Warm Glow in All Parts? Building Local Cause-Affinity as a Strategy for Promoting Charitable Giving

\section{Introduction}

At the launch of the Giving Green Paper on 29 December 2010 government ministers talked in terms of a 'warm glow' which may come from acts of altruism (the first quotation above). This notion of the 'warm glow' is a well-established tenet of economic and behavioural theories of giving (Mayo and Tinsley, 2009). To use Adam Smith's words, donors gain simply 'the pleasure of seeing it' (Smith, 1759. p. 9) (the second quotation above). This of course brings to mind two principles which may appear incompatible and are set out in both Adam Smith's two published books (The Theory of Moral Sentiments, 1759; The Wealth of Nations, 1776) and also perhaps reflected in modern Conservative policy: on the one hand the role of benevolence and altruism as reflected in the Big Society agenda, and on the other the rationality of economic actors and the role of self-interest reflected across agendas of deficit reduction and austerity. Time seems to have played a part in these changes: for Adam Smith from an idealistic stance to one of materialism; whilst for the Conservative Party, the move from a period of brand detoxification in opposition for electoral appeal to the pragmatics of government and a central neo-liberal political agenda. This brings us to the third quotation above, that despite policy rhetoric, giving is a poor substitute for welfare in terms of helping those most in need.

This paper does not seek to reconcile differences in Adam Smith's two great works: the Theory of Moral Sentiments which argues that individuals are naturally benevolent and altruistic; and The Wealth of Nations, that individuals are rational economic actors primarily considered with maximising their personal utility. At least, this is the common reading of these two works. This paper seeks to return a debate on charitable giving from a domain which has given considerable attention to the economics of charitable giving (the rational actor thesis) to an arena which considers social, political and institutional factors (the benevolent and altruistic human thesis).

Our interest here is with how we understand giving at a local level and the relevance of the two broad theories of giving (illustrated in Smith's works) to local geographical scales, where for instance we may seek issues of place identity or local personal connection invoked as strategies to promote giving. An obvious starting point to such a discussion is to show that patterns of giving (in the UK) do vary region by region but that these differences can largely be explained by differences in income level. Nonetheless we find that there is been growing interest in local level initiatives to promote giving. These are not yet common or widespread but they do reveal how local community and voluntary sector actors are seeking to address gaps left in welfare provision. We term these approaches 'local cause affinity' and draw on examples of local case study research to illustrate them.

This paper draws on two reports published in 2013 (Bashir et al., 2013a, 2013b). Firstly, we developed a set of data considering spatial distribution issues. These data are taken from the following sources: a survey of 1,403 VCS organisations in Greater Manchester; qualitative insights from interviews with VCS umbrella organisations and other local stakeholders; secondary data on SME attitudes to locality and giving; and secondary data on the spatial distribution of enterprises and VCS organisations. Drawing these threads together allows for exploratory analysis of the issues outlined above. The limitations of these data should also be noted, however. For instance, they do not provide a cohesive dataset on the issue of local (business) giving - the data were collected with a range of different aims in mind - and as a result some questions posed by the exploration of the data inevitably remain unanswered. Nonetheless, pulling the data together does allow for a consideration of a number of key questions; and in using a range of sources it is possible to triangulate results and consider hypotheses. 
p. 141. A Warm Glow in All Parts? Building Local Cause-Affinity as a Strategy for Promoting Charitable Giving

Secondly we draw on locality based case study research. This involved interviews with representatives from local support and development organisations (VCS 'infrastructure', such as councils for voluntary service) and representatives from their partners in developing local giving initiatives.

The paper considers the following in turn: the policy context for giving in the UK; variations in patterns of giving; and case study evidence of local approaches to giving and how local 'cause affinity' might develop. The conclusion reflects on the usefulness of the idea of local cause affinity, comments on possible policy responses and suggests further lines of research enquiry.

\section{Explaining Giving in the UK}

Considerable research has been undertaken into the role of giving at a national level in the United Kingdom, notably work undertaken by McKenzie and Pharoah (2010). This follows a long tradition of research into giving and philanthropy in the United States (Wolpert and Rheiner, 1984), where the role of giving to non-for-profit organisations plays a far more significant part of the sector's funding. Recent work by McKenzie and Pharoah also points to interesting regional and national variations within the United Kingdom, both in the propensity to give and the proportion of the population giving. These variations cannot be simply explained by variations in income or socio-economic group, which might be expected (i.e. explanations due to compositional variation; see for example UK Giving, CAF and NCVO, 2010). However, it must also be stressed that giving as a share of national income has changed relatively little.

The Coalition Government has placed great emphasis on social action through the unifying policy idea of the Big Society (Cabinet Office, 2010; see also Crisp et al., 2010, Pharoah, 2011 and Wells et al., 2011a and 2011b). A key theme of this is the shift in the responsibility welfare provision from the state to society. This also includes the funding of social action and more specifically the voluntary and community sector.

The Giving Green and White Papers (Cabinet Office, 2011, 2012; see also Speller, 2011) identify an array of areas in which giving in terms of time and money may be increased. Of particular significance is the emphasis placed on understanding the motivations of givers, and how understanding individual and collective behaviour is essential to increasing the level for giving in the United Kingdom. Indeed, authors such as Breeze (2010) have suggested that understanding the decision making process of giving should be the starting point for explaining variations in giving. The Giving Green Paper (2011) draws heavily on behavioural economics or 'nudges', to show how policies can be re-designed to increase utility or welfare outcomes. Examples of such nudges include rounding-up payments to whole numbers where purchasers of goods can donate the difference to charity; options to make donations at ATMs; (also known as cash points) and the use of social media to show who else is giving to a charity (for instance someone's 'friends' on Facebook).

However, relatively little is known about giving at a local level, either by individuals or businesses, and how this might be developed. Indeed the Giving Green Paper gives no consideration to local and regional differences in giving.

The 2011 Philanthropy Review reflected this trend of not considering local giving. Its recommendations were largely concerned with recommended actions which should be taken at a national level, including:

- making it easier for people to give including the promotion of payroll giving, the introduction of charity bank accounts and gift aid on small cash donations 
p. 142. A Warm Glow in All Parts? Building Local Cause-Affinity as a Strategy for Promoting Charitable Giving

- encouraging giving including living legacies, extending tax relief to all gifts of assets to charities and full tax reduction on gifts in cash (including small cash donations)

- changing culture including sharing giving data, introducing giving into the education curriculum, and running a national Give More campaign.

A very ambitious goal of the Philanthropy Review Board's report is that these interventions have the potential to treble the level of giving between 2011 and 2015.

Furthermore, attention to the role of businesses as supporters of charity is largely confined to large businesses, through mechanisms such as the release of staff on a pro bono basis, payroll giving, and corporate sponsorship of a charity. More broadly these activities often come under a Corporate Social Responsibility (CSR) banner of large businesses. Again, relatively little research has been undertaken of the implications of business giving at a local level, and in particular the role Small and Medium Enterprises (SMEs) might or might not play. Exceptions to this include:

- the DTI's (2003) Engaging SMEs in Community \& Social Issues

- research by former Labour MP Tom Levitt into SME community engagement in York and Bradford. This was funded by the Joseph Rowntree Foundation.

It is apparent that there is very little evidence into the scale or trends in giving by SMEs at a local level in the United Kingdom.

Despite this, business giving has become a key component of the Government's strategy to promote civil action. Whilst there is an array of research based on case study evidence (see for example Beth Breeze's work on giving by High Net-Worth Individuals (Breeze, 2011), research on Family based Foundations (Breeze, 2009) and Barclays' research on the intentions of high value account holders) (Barclays, 2011) none of this looks at businesses themselves.

Research into why small businesses engage in communities tends to reveal some striking patterns. A good example of this is research by Madden, Scaife and Crissman (2006) on SME engagement in communities in Australia. The research revealed the following:

- small firms have an interest in supporting local communities

- it is useful to combine individual and corporate motives for support as most small businesses are privately owned and ownership and management roles are combined

- some small businesses receive a lot of requests for support from charity fundraising campaigns. Most requests are ignored as a result

- support is less likely to be about contributing financially, and more likely to be about giving expertise, time and materials.

The authors go on to make the case for better dissemination of best practice to businesses on how to engage in communities.

Moreover, there may be a considerable degree of consistency between the donor preferences of SMEs (and especially their owners) and the donor preferences of individuals. In exploring the latter, Beth Breeze notes that people do not give based on an assessment of need: rather, they prefer to support causes that mean something to them. As such, four common non-social needs based criteria are identified (Breeze, 2010, p. 9): 
p. 143. A Warm Glow in All Parts? Building Local Cause-Affinity as a Strategy for Promoting Charitable Giving

- giving decisions are 'motivated by donors' tastes, preferences and passions linked to an individual donor's social experiences'

- donors' 'personal and professional backgrounds shape their giving decisions and choice of beneficiaries'

- 'donor perceptions of charity competence' are important but these tend to be based on views regarding the efficiency of how they use their money, including the quality and quantity of direct mail'

- 'donors are also motivated by a desire to have a personal impact, such that their contribution makes a difference and is not 'drowned-out' by other donors or government funding'.

In this context it is important to understand that giving and philanthropy are supplyled (i.e. the opposite to taxation) and we should not overestimate the extent to which donors act rationally in their giving decisions which are often 'taste based' rather than 'needs-based' (Pharoah, 2011). What can be inferred from this for local giving? The first and final bullet points suggest the desire of a donor to have an impact in places where they have a personal association, or where their donation might be seen as important. Strategies targeting local giving and philanthropy would therefore do well to bear in mind these two possible motivations when considering how to attract donors. It is from this which we are interested in understanding how cause affinity might develop at a local level. We define local cause affinity as the importance and attachment individuals give to charitable causes at a local level.

Despite relatively limited evidence on the extent of giving in the UK, the Government is rolling out programmes to support giving. These include the promotion of giving by businesses through the Cabinet Office 'Innovation in Giving' programme, delivered by NESTA as part of their Public Services Lab programme. This includes a new strand of work in 2013 to increase the level and scale of community contribution from business, including SMEs. They correctly highlight that this is an underdeveloped area (compared to the major corporate sector). In this arena we explore the role local cause-affinity might play and what it may look like.

\section{A warm glow in some parts: the geography of giving}

At the heart of this exploratory paper is a concern for the lost geographies of giving. This is expressed in four ways: (1) a concern for the ascalar nature of contemporary policy discourse on giving, which does not pay sufficient attention to differentiating between the national, regional, local or community scales of activity; (2) a concern for the spatial distribution of giving, and the inequalities therein; (3) a concern for the discourse of 'place' in the generation of 'cause affinity'; and (4) a concern for resource flows between and within places. The first of these concerns is an overarching issue, addressed throughout the paper, although some specific scale-related threads are picked up later on in this section.

In order to address the initial point regarding a need for attention on the local it is important to consider what the general picture is with regard to local giving. The headline finding from the empirical data being drawn on in this paper (outlined above) is that relationships at a local level between individuals and businesses, and the VCS are weak. While relationships between some individuals or businesses and some VCS organisations are strong and represent high value both in terms of income and nonfinancial benefits, the general picture is much less positive. This is demonstrated through a range of findings from the survey of Greater Manchester VCS organisations. 

Giving

For instance, only 19 per cent of respondents thought that local commercial businesses were a positive influence on their organisation's success (compared to 39 per cent with local authorities), which is reflected in income data: just nine per cent of respondents identified business donations and sponsorship as a source of funds, while income from business donations and sponsorships came to just two per cent of overall income across respondents. Only seven per cent of organisations received 50 per cent or more of their income from business donations and sponsorship. 82 per cent of those receiving any income from business received less than $£ 10,000$. To all intents and purposes, most VCS organisations and businesses inhabit different worlds. They do not share networks, and resources do not flow between the two, except with VCS organisations as a client of business suppliers. The topology of local places in this sense is of relatively discrete networks operating in isolation from one another.

Much of what individuals and local businesses give to charities does not come by way of financial gifts: instead they may offer time, skills or other forms of physical gift. Relationships are complex and likely to take different forms. Nonetheless, when given opportunity to qualitatively describe their relationship with local businesses, of those that commented on a positive relationship with commercial businesses (132 out of 171 qualitative responses), 99 commented that this relationship was minimal. Relationships were characterised by low-level informal support, typified by the donation of raffle prizes, discounted prices for services or rent, sponsorship, support from supermarkets (allowing charity collections/bag-packing, food donations) and providing volunteers (especially for environmental projects). Invaluable as this support may be, it does not provide the necessary conditions for sustainability in charitable organisations. This is not a normative statement suggesting necessarily that businesses should be responsible for doing so: rather, current conditions do not offer sufficient basis for local business giving to form a reliable core element of VCS funding. Furthermore, there was a tendency towards single relationships with one business, not multiple connections. There was no business-VCS ecosystem, which is reflected in the qualitative responses from the 30 respondents who made more critical comments. Here, respondents outlined how the two sectors did not understand one another; that businesses preferred to give to national charities; and in some cases commercial organisations were seen as competitors. Overall the barriers to engaging local business were seen as too big: '[it is] difficult to build long standing, meaningful relationships' (respondent, Greater Manchester).

Yet this overall picture masks particular points where local businesses and local VCS organisations do come together. In financial terms, some organisations were able to lever considerable levels of funding from the private sector: 18 per cent received $£ 10,000$ or more per year, and two organisations received more than $£ 100,000$ from businesses. Both of these were high-value capital-based projects, one being a new state of the art youth centre, and the other being an arts and heritage trust in the process of renovating an abandoned theatre. Similarly, large organisations were more likely to receive income from business donations and sponsorship, and linked, registered charities were more likely to receive funding. In terms of their activities, VCS organisations working in the arenas of sport and leisure (especially specifically sport, leisure and social clubs) and art, heritage and culture were more likely to be in receipt of income in comparison to their distribution across Greater Manchester.

This overview does not depict a scene whereby local business are actively engaged in a civil society working to encourage the blossom of 'a thousand flowers' towards meeting wider societal goals. Instead, we see small scale exchanges that suggest not so much relationships as one-off or ad hoc interactions. Larger scale, longer-term interactions are based around projects and organisations that combine an appeal to intrinsic or moral value with sign or 'brand' value: larger, more well-known charities, 
buildings, museums, sports clubs and so on. This suggests a challenge for the VCS to find ways of appealing to different, mutually reinforcing forms of value.

There is an underlying issue here, which goes against the grain of current policy thinking. It is rare for VCS organisations to achieve a comprehensive 'switch' from being largely publicly to largely privately funded (Teasdale, 2010). Indeed, by the nature of what many VCS organisations provide, intuitively such a switch might be considered implausible - VCS organisations have emerged in response to market failures and the gaps left by market or state (Wells, 2013). Those organisations that specialise in service provision tend to be fulfilling state functions under the auspices of collective provision, and are state funded in part because they would not otherwise be fulfilled (and/or because the state is not able to fulfil the duty directly). This brings about a wider set of questions regarding giving cultures and the variegated connections between local business and the local VCS.

Stemming from this, a fundamental point to make is that the spatial distribution of the VCS and in particular registered charities, enterprises and giving is uneven. This includes financial resources, but more generally the underlying capacity and capabilities for giving and fostering relationships between the VCS and local communities are unevenly distributed. A broad point to make is that wealthier places tend to have a larger base of registered charities (see McKenzie and Pharoah, 2010). This reflects a series of papers by David Clifford and John Mohan (see for example Clifford et al., 2013) highlighting the existence of charity 'deserts' and that there are proportionately fewer registered charities in poorer places. And, in line with this, places with a greater per capita number of enterprises tend also to have a greater per capita number of registered charities (Cabinet Office, 2010; National Statistics, 2013): comparing registered charities per capita with enterprises per capita across local authorities in England generates a strong positive Pearson's correlation coefficient of 0.74 .

As a whole, this raises questions about the ability for the VCS to effectively (a) develop capacity, and (b) generate funding from other sources in order to fill in additional gaps in state provision created by public sector cuts in areas where the 'need' for public service provision is greatest. Indeed as Christina Beatty and Steve Fothergill (2013) show it is the poorest places in the United Kingdom where the impact of welfare reform cuts will be greatest. That is, areas with greater need for economic and environmental 'stimulus', high levels of people in receipt of disability benefits, high unemployment, low levels of educational achievement, higher crime rates and so on.

But there are anomalies within this analysis, and mapping the relative distribution of the VCS organisations and enterprise rates helps to highlight these outliers geographically. Figure 1 shows the difference between enterprise rates and registered charity rates when each variable is ranked and the differences compared. A positive score indicates that enterprise rates are relatively higher than charity rates, and a negative score indicates the opposite scenario. It shows that the rural 'extremities' of England - for example, Cumbria, Northumberland, and the South West - have a higher proportion of registered charities that might be expected based on the overall correlation of VCS and enterprise rates. It also shows two patterns regarding areas with lower levels of VCS organisations than might be anticipated. The first of these is seaside towns (Blackpool, North East Lincolnshire - home of Cleethorpes Bournemouth, Poole and Southend-on-Sea); the second is the peripheries to the UK's three largest cities: London, Birmingham and Manchester. 
p. 146. A Warm Glow in All Parts? Building Local Cause-Affinity as a Strategy for Promoting Charitable Giving

\section{Figure 1: Differences in enterprise and VCS ranks by English local authority}

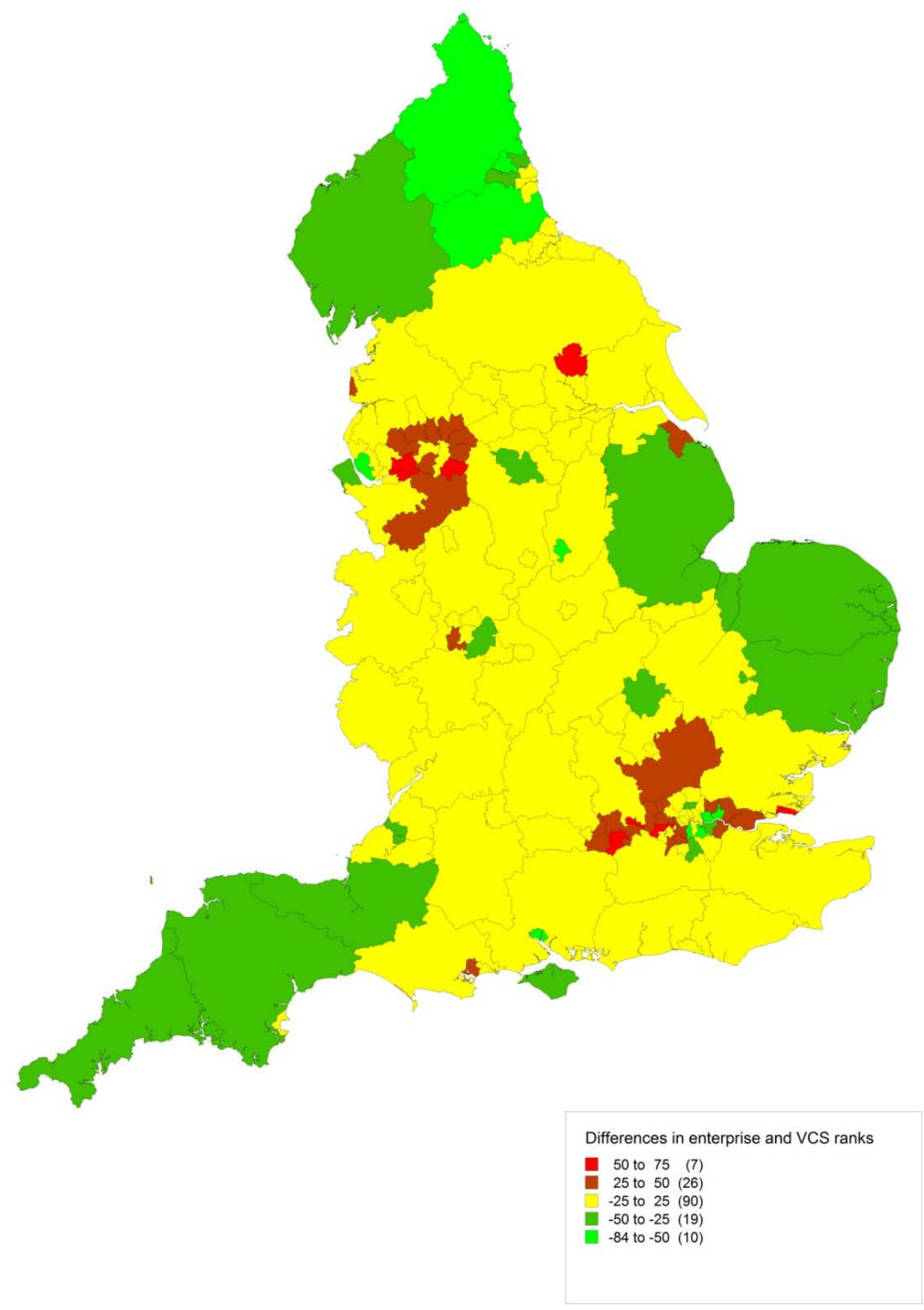

Two points are worthy of particular consideration here. First, it suggests that the spatial distribution of different types of enterprise appears to have some link to registered charity success. The enterprise rates in seaside towns are skewed by large numbers of businesses serving the seasonal tourist trade, which this data would suggest do not interact strongly with registered charities (nor generate relatively high 
p. 147. A Warm Glow in All Parts? Building Local Cause-Affinity as a Strategy for Promoting Charitable Giving

levels of wealth). Findings from stakeholder interviews suggest that VCS organisations in areas with relatively high numbers of firms with professional services had greater success in engaging with businesses. Each of the seaside towns listed above were in the lowest 30 per cent of English local authorities in terms of the size of their professional service sector.

Second, the lower distribution of registered charities compared to enterprises in the peripheries of large city-regions raises the issue of flows between and within places. Looking at the geographic distribution highlighted in Figure 1, we can hypothesize that there is some degree of 'sucking' from urban peripheries to the core in terms of giving. The existence of larger charities, and/or national charities' headquarters in the UK's largest cities, and especially London, may have an effect that is disproportionate to their size (in numbers) and have an adverse effect on registered charities in surrounding areas.

A central point of this paper is that scale is important in that national policy on giving needs to also consider the local. Issues of variable capacity between and within places also raise questions regarding scale and the relationship between national, regional and local and the relationship between business and the VCS within this. Part of the answer here lies not only in national level policy, but in the work of local state, non-state, community organisations and individuals in generating capacity and engaging businesses and individuals at the local level.

\section{The Growth in Local Giving Practices}

The level of giving in the UK as measured as a proportion of national income has remained reasonably constant: it is higher than many other European countries, but considerably behind levels in the United States. Much of these differences can be explained by deep seated cultural and institutional norms, which can be very resistant to the most well considered government initiatives. Despite this the Coalition Government, more than its predecessors, has championed giving as an important expression of civil society. It has done so with scant reference to the role of places.

From a limited review of local responses, we found evidence of either quite longstanding attempts to raise local giving or initiatives which have emerged over the last five years. The following list provides some examples:

- Community Foundation Tyne \& Wear and Northumberland: established in 1988, this is one of the longest established and high profile community foundations. Its aim is to be a hub for community philanthropy, 'supporting giving that strengthens communities and enriches local life'

- Kensington and Chelsea Foundation: established in 2008, by 2013 it had raised $£ 1.4$ million to support local charities working in deprived areas of the borough

- Sussex Community Foundation: established in 2006, the Foundation sought to provide a mechanism for individuals, foundation and other groups to give money to address deprivation across Sussex. It has received support from the American Express Foundation, Barclays, the Batty Charitable Trust, the Henry Smith Charity, West Sussex County Council and eleven individual donors

- Islington Giving: The Islington Giving campaign was inspired by Invisible Islington: Living in Poverty in Inner London a report. This was commissioned by The Cripplegate Foundation in 2008. The report shows the concentrations of poverty in the borough. The fundraising campaign seeks to raise over $£ 3$ million in three years 
- Merton Means Business: an initiative seeking to link local businesses with local voluntary activity for mutual benefit. It is a joint initiative of the Merton Chamber of Commerce and the Merton Voluntary Service Council

- Tameside4Good: an initiative of Community and Voluntary Action Tameside. It has sought to develop a strong brand which is readily understandable by business, VCS and residents.

One example illustrates how local cause affinity might develop. In Islington, the VCS and other stakeholders came together to commission a research study called Invisible Islington: Living in Poverty in Inner London (Rocket Science, 2008), which revealed the large disparity in wealth within the London borough and that there was little interaction between the wealthiest and poorest. The research was seen by local stakeholders as a trigger for local action to generate flows in giving towards the deprived communities from wealthier communities. This provides a possible example whereby local action has helped to challenge and shape the prevailing giving culture towards more 'needs' based giving.

All these initiatives take different institutional forms, ranging from community foundations through to projects developed by local support and development organisations. They see to have some common features:

- building local capacity for giving and philanthropy: building relationships with other key stakeholders in giving was important, whether between a community foundation and support and development organisation, with chambers of commerce or with local authorities. Local partnership was seen as an important starting point but also something necessary to sustain the initiatives

- communications and relationships: attracting donations from high net worth individuals or businesses was found to be about building and managing relationships. It was found that cold calling rarely worked and approaches had to be far more personalised and based on networks of trust

- networks between frontline voluntary organisations and donors: Professional services such as accountants and solicitors were found in some cases to have important roles to play. In some cases they were able to signpost potential donors to the local cause rather than to a major national charity

- leadership, staff and trustees: chief executives and trustees of charities were found to play an important role both in developing networks for local giving and philanthropy but also in leading a new or different approach to funding

- building connections and managing relationships: the initiatives all identified that it was necessary to spend time building connections, whether with donors or frontline voluntary organisations

- information, marketing and media: these initiatives all gave considerable prominence to building a strong local brand. This could then be used consistently to promote the initiatives, whether in contact with local funders or in work with local media

- technologies for giving: the initiatives all had considered the specific supporting technologies they needed to support giving. This included payroll giving, the use of Gift Aid, using localgiving.com, and the use of social media they used as appropriate to each initiative.

The use of mixed or multi-media communications was found to be an important aspect of the local areas in which we conducted fieldwork. This included the strong use 
of personal testimony but also very clear and powerful representations of the causes being supported. This was supported with some simple quantitative evidence. As such communications appeared to have a logical sequence from awareness raising and general communication through to much more personalised and deeper communications. This may have been deliberate or accidental but it can be seen that a strong emphasis was placed on building affinity with local causes and then providing feedback, possibly with encouraging 'warm glow' in donors in mind.

The rise of systematic approaches to promote local giving is a striking and a largely recent phenomenon. Even the most well established initiatives in this area, such as the Community Foundation Tyne \& Wear and Northumberland, are only 25 years old. These initiatives, alongside the longstanding actions of some charities which have long worked at a local level (such as local hospices), suggest that local places may be an important arena for building local cause affinity. What is striking therefore is that this phenomenon has almost been entirely overlooked in national policy debate.

The local initiatives considered work in very different contexts. Islington, Kensington and Chelsea, Merton and Sussex are to a large extent prosperous places with pockets of severe disadvantage. Tameside and Tyne \& Wear are very different. They are largely disadvantaged places with some pockets of prosperity. Nonetheless the initiatives in both places appear to date to have been very successful in providing a basis for localcause based giving. They are realistic that this may not change the fortunes of these places but it may do two things. Firstly, they help raise funds for voluntary action to support need and secondly they contribute at some level to the building of place identity. Whether this means there is a 'warm glow' for both those that give and for these places is a matter for further empirical research.

\section{Conclusion: taking local cause affinity further?}

In our reports on local giving (Bashir et al., 2013a, 2013b) we argue that it is difficult to change levels or indeed patterns of giving in the short term. These reports discussed that giving is underpinned by some quite deep seated norms of behaviour and institutional and cultural settings which change slowly. Nonetheless, we argue both the VCS and government has been right to explore ways in which giving could change, even if the proposed instruments to do so may have little net effect. We began the paper with reference to Adam Smith's two great published works, and how the arguments in each can be difficult to reconcile. In some ways these frame the tensions between hope and the possibilities of altruism in support of others, and the rational economic act of seeking to maximise personal utility, with limited regard for wider consequences.

Examples given above referred to the role of local infrastructure organisations in helping to coordinate and facilitate networks and resources to build relationships between the VCS and local businesses. Such initiatives seem important in any attempts to develop greater capacity within the VCS to engage with business and potentially shape giving cultures. But the evidence also suggests that it is important to have similar business-led bodies engaged, such as local chambers of commerce - as was the case in Merton - and Local Enterprise Partnerships (LEPS).

Such efforts help in the search for a now relatively old-fashioned geographic policy notion of institutional thickness, a variant on what VCS scholars may term the civic core, which may in turn be mobilised to bring about long-term cultural change and development of in-depth relationships between local VCS organisations and local businesses. But, it should also be stressed that the civic core has changed very slowly over time. Long-term development of local facilitative, coordinating capacity is central to this. But these developments continue to fight against the tide in places where there 
p. 150. A Warm Glow in All Parts? Building Local Cause-Affinity as a Strategy for Promoting Charitable Giving

is - simply put - less to go around. A longer term goal might therefore be to work to develop a culture of giving that is not necessarily about a shift towards local giving, but instead towards giving between locales (rather than flowing towards national bodies). In other words, there is a need to develop horizontal, spatially redistributive giving between places as well as within places.

In the paper we sought to explore the usefulness of 'local cause affinity', both normatively as a model for local VCS organisations but also more tentatively as a research project. As a normative guide we argue that most such attempts appear to have a starting point which involves elements of leadership, common cause, strategy and partnership. The argument here is that local giving does not simply emerge but requires action on the part of individuals working in places to understand and address social needs. Whether these are templates for others to follow is another matter. But as the wider literature on giving has shown, giving is an act primarily rooted in individuals' personal preferences and tastes, and not on what might be the most pressing social needs.

Research into the emergent phenomenon of local giving, and the role of causeaffinity approaches, needs to consider the following. Firstly, we need to explore the development of local giving initiatives, the actors involved, their interactions and how allegiance/conflict develop and are reconciled. A starting point would be to begin to build consistent datasets on giving at a local level. Secondly, it may be possible to evaluate the effectiveness of different approaches, taking into account whether some approaches work better in some places than others. Thirdly, whilst localities provide important sites for study, there are risks in seeing them in isolation. A key concern here would be around whether local giving initiatives increase the overall level of giving (locally and nationally) or whether they in effect displace giving to other causes (again, whether locally or nationally). Finally, we know little about the 'warm glow' of altruism and to what extent local giving may generate greater psychological benefits for the individuals involved or indeed for localities.

In the Theory of Moral Sentiments, Adam Smith asks when is it that humans would sacrifice their own interests to the greater interests of others (1759, p. 137). Rejecting traditional Christian teachings he suggests the following:

It is not the love of our neighbour, it is not the love of mankind, which upon many occasions prompts us to the practice of those divine virtues. It is a stronger love, a more powerful affection, which generally takes place upon such occasions; the love of what is honourable and noble, of the grandeur, and dignity, and superiority of our own characters (Smith, 1759, p. 137).

In this response we see a glimpse of how Adam Smith reconciles his two great works. It helps us see a more rationalist logic and less sentimentalist logic to giving which policy makers need to remember. It is this understanding we should hold when analysing altruism and giving policy, whether conducted locally or nationally.

* Correspondence address: Peter Wells, CRESR, Unit 10, Science Park, Howard Street, Sheffield, S1 1WB. Email: p.wells@shu.ac.uk.

\section{References}

Bale, T. (2008) A Bit Less Bunny-Hugging and a Bit More Bunny-Boiling? Qualifying Conservative Party Change under David Cameron. British Politics. 3, 270-299. 
p. 151. A Warm Glow in All Parts? Building Local Cause-Affinity as a Strategy for Promoting Charitable Giving

Barclays (2011) Barclays Wealth 2011 UK Wealth Map. London, Barclays http://www.barclayswealth.com/insights/assets/pdf/2011-UK-Wealth-Map.pdf

Bashir, N., Dayson, C. and Wells, P. (2013a) Local Giving: possibilities for support and development organisations. Sheffield: CRESR, Sheffield Hallam University.

Bashir, N., Dayson, C., Eadson, W. and Wells, P. (2013b) Local Business Giving: between the raffle prize and a new source of funding. Sheffield: CRESR, Sheffield Hallam University.

Beatty, C. and Fothergill, S. (2013) Hitting the poorest places hardest. The local and regional impact of welfare reform. SHU: CRESR. Report available at: www.shu.ac.uk/research/cresr/sites/shu.ac.uk/files/hitting-poorest-placeshardest 0.pdf Downloaded from the internet on 21 November, 2013.

BITC (2003) Engaging SMEs in Community and Social Issues. London: BITC. http://www.bitc.org.uk/resources/publications/engaging_smes.html

Breeze, B. (2009) Natural Philanthropists: Findings of the Family Business Philanthropy and Social Responsibility Inquiry. London: Institute for Family Business.

Breeze, B. (2010) How Donors Choose Charities Findings of a study of donor perceptions of the nature and distribution of charitable benefit, CGAP Occasional Paper 1.

Breeze, B. (2011) The Coutts Million Pound Donors Report 2011. London: Coutts.

Cabinet Office (2010) National Survey of Charities and Social Enterprises. London: Cabinet Office

Cabinet Office (2011) Giving Green Paper. London: Cabinet Office.

CAF and NCVO (2010) UK Giving. London: CAF. https://www.cafonline.org/pdf/UK Giving 2011 Full Rep.pdf

Clifford, D., Geyne-Rahme, F. and Mohan, J. (2013) Variations between Organisations and Localities in Government Funding of Third-sector Activity: Evidence from the National Survey of Third-sector Organisations in England'. Urban Studies, 50, 5, 959-976.

Crisp, R., Macmillan, R., Robinson, D. and Wells, P. (2009) Continuity or Change: considering the policy implications of a Conservative government. People, Place and Policy Online, 3, 1, 58-74.

Levitt, T (2013) The Social SME. A Study of Small Businesses and Selected Social Responsibility Issues in Bradford and York. York: Joseph Rowntree Foundation. Report is available on the internet: http://sector4focus.co.uk/home/smes-in-thecommunity-my-jrf-report/

Madden, K., Scaife, W. and Crissman, K. (2006) How and why small to medium size enterprises (SMEs) engage with their communities: an Australian study. International Journal of Nonprofit Voluntary Sector Marketing, 11, 49-60.

McKenzie, T. and Pharoah, C. (2010) UK household giving - new results on regional trends 2001-08. CGAP Briefing 6 . www.cgap.org.uk/uploads/reports/CGAP_Briefing_Note_6\%20(Regional\%20Givin g).pdf

Mayo, J.W. and Tinsley, C.T. (2009) Warm glow and charitable giving: Why the wealthy do not give more to charity? Journal of Economic Psychology, 30, 490-499.

National Statistics (2013) Business Population Estimates for the UK and the Regions. London: National Statistics.

Pharoah, C. (2011) Private giving and philanthropy - their place in the Big Society. People Place and Policy Online, 5, 2, 65-75.

Philanthropy Review (2011) A call to action to encourage more people to give and people to give more. Recommendations from the Philanthropy Review, June 2011. www.philanthropyreview.co.uk/Philanthropy\%20Review\%20Charter.pdf

Rocket Science (2008) Invisible Islington: Living in Poverty in Inner London. London: Cripplegate Foundation. Report downloaded from the internet on 22.11.2013: www.cripplegate.org/wp-content/uploads/Invisible-Islington-Nov08.pdf 
p. 152. A Warm Glow in All Parts? Building Local Cause-Affinity as a Strategy for Promoting Charitable Giving

Smith, A. (1759) The Theory of Moral Sentiments. Cited from text edited by D.D. Raphael and A.L. Macfie, (1976). Oxford: Oxford University Press.

Speller, M. (2011) Giving in Local Communities. London: Cabinet Office.

Wells, P., Gilbertson, J., Gore, T. and Crowe, M. (2011a) A Big Society in Yorkshire and Humber? Leeds: Regional Forum.

Wells, P., Gilbertson, J., Gore, T. and Crowe, M. (2011b) Measuring the Big Society: approaches, problems and suggested improvements. Leeds: Yorkshire and Humber Forum.

Wells, P. (2013) When the third sector went to market: the problematic use of Market Failure to justify social investment policy. Voluntary Sector Review, 4, 1, 77 94(18).

Wolpert, J. and Rheiner, T. (1984) The Philanthropy Marketplace. Economic Geography, 60, 3, 197-209. 